\title{
Editorial \\ LA PAZ CONSTRUYE Y SE CONSTRUYE
}

La paz es un proceso constituido por gentes, su posibilidad de acceso a bienes naturales y sociales. Naturales porque es un bien al que todos de forma natural tenemos derecho, pero no acceso, desde el mismo momento en que nacemos. Sociales porque una sociedad en armonía concede y reparte formas de vida dignas entre todos sus miembros, partícipes en común de proyectos humanos.

Es un proceso que construye sociedades y personas, pero que debe estar constituido e institucionalizado y también debe ser un hábito y un dato. Porque, por ejemplo, si una vez alcanzado no se mantiene, y en ello tienen que ver las personas entidades y hábitos, corre el riesgo volver a perderse. Muchos defensores de la paz mantienen que esta se hace al margen de las instituciones y vigilantes. No es así, a no ser que las utopías se conviertan (pasado el tiempo) en distopías.

La violencia surge cuando el poder está en peligro, siguiendo a Hannah Arendt, de ahí que hayamos dicho anteriormente que el proceso (de Paz) debe estar constituido e institucionalizado.

La legitimación de la violencia no es posible en un estado de derecho con igual posibilidad entre sus miembros.

El fenómeno de la Violencia en Colombia, según Alma Guillermoprieto (último premio Princesa de Asturias en Comunicación y Humanidades), es la conjugación del narcotráfico con sociedades indefensas y la corrupción, la que genera el negocio del narcotráfico.

Las víctimas deben mostrarse, para recomponer fractura social, en un periodo de tiempo inmediato. De esta forma, la transición hacia una sociedad en paz es liberadora y posible. Sin embargo, si se produce una transición que posponga las heridas a generaciones futuras, la sociedad continúa resquebrajada en su fondo. Conocemos casos muy cercanos. Las heridas guardadas durante varias generaciones terminan enquistándose y los ataques, pasado el tiempo, se convierten en nuevos focos de conflicto que se arrojan de forma poco sesuda en la convivencia de la sociedad futura, arriesgando de forma cíclica la cohesión. La mediación es posible si se hace allí y ahora como un proceso continuo donde no exista posibilidad de fractura social. Aunque ello no es tarea fácil. Revelar la verdad sobre los hechos violentos es una oportunidad hoy, y si se pospone, se puede convertir en un error. Las sociedades no están compuestas de partes maleables que se puedan fundir y seccionar al igual que el ser humano.

Son muchos años (cincuenta y dos), y muchas víctimas de actos de violencia (más de siete millones) entre muertes, desapariciones, desplazados, etc. los que ha sufrido Colombia.

Los testimonios de la Comisión de la Verdad deben ser fiables, no manipulables, ni viciados por visiones confusas o de forma temporal. Hay que garantizar el restablecimiento en el presente.

Si no es posible el desmantelamiento de organizaciones violentas, la corrupción que genera el narcotráfico, la constitución de jueces representativos, la existencia de líderes sociales, la paz se verá comprometida. La igualdad se constituye con enfoques de equidad, no existe posibilidad de curar las heridas sin la equidad. La igualdad está unida inevitablemente a la

No 6, 2018. Página 9 
no violencia, porque esta última surge del abuso de poder, por imposición, sin posibilidad de elección.

La educación, y la extensión de una cultura de paz es clave en este proceso. Se garantiza mediante modos y formas, hábitos valores y normas, elementos simbólicos con el distintivo paz, compartidos de forma permanente. Una vez construida, la paz construye a las personas de ese estado, les devuelve su identidad.

Quienes participan en el presente número (principalmente por su edad), no son expertos que puedan dar lecciones sobre procesos de paz, pero sí son especialistas que forman parte de un engranaje necesario para engrasar sus mecanismos hoy y mañana. Y eso es imprescindible. Este número se planteó como un ensayo, un laboratorio académico. Por eso, sus coordinadoras fueron escogidas entre graduados que había cursado en el seminario de Género y Paz el Master en Cultura de Paz, Conflictos, Educación y Derechos Humanos en la Universidad de Cádiz. Es muy prometedor para sociedades futuras, que en las universidades se trabajen estos temas, que se trabaje en la construcción por tanto de sociedades con el rasgo diferenciador de la paz. Por eso ReSed optó por plantear este monográfico entre alumnos y alumnas que acababan de graduarse. Es un gusto decir que son una promesa, y también que la coordinación del monográfico fue realizada por mujeres.

Las aportaciones a este número exponen experiencias de interés en sociedades que han salido del conflicto, u ofrecen argumentaciones a tener en cuenta en la construcción de la paz. Son propuestas atrevidas y originales, algo que desde la revista pensamos esencial para configurar nuevas e innovadoras alternativas.

Como en otras ocasiones, la revista publica artículos en otros idiomas, acompañados de la traducción al español, una apuesta que pensamos esencial en la internacionalización de los temas que trata.

Agradezco por tanto que en este número hayan participado tantas personas preocupadas por la construcción de la paz, antiguas alumnas, y antiguos profesores, con inquietudes reales.

\section{A. Beatriz Pérez-González Universidad de Cádiz}

